Gerhard Schurz Logik 


\section{Gerhard Schurz}

Logik

Grund- und Aufbaukurs in Aussagenund Prädikatenlogik

2., korrigierte und erweiterte Auflage 
ISBN 978-3-11-069714-8

e-ISBN (PDF) 978-3-11-069739-1

e-ISBN (EPUB) 978-3-11-069747-6

Library of Congress Control Number: 2018949258

\section{Bibliografische Information der Deutschen Nationalbibliothek}

Die Deutsche Nationalbibliothek verzeichnet diese Publikation in der Deutschen Nationalbibliografie; detaillierte bibliografische Daten sind im Internet über http://dnb.dnb.de abrufbar.

(C) 2020 Walter de Gruyter GmbH, Berlin/Boston Umschlag: Ausschnitt aus Wassily Kandinsky, Vassily_Kandinsky,_1927_-_Molle_rudesse.jpg, Wikimedia Commons, Public Domain.

Satz: Textbüro Vorderobermeier GbR, München Druck und Bindung: $\mathrm{CPI}$ books $\mathrm{GmbH}$, Leck

www.degruyter.com 